\title{
2. Theoretical Approaches to Retirement and Early Exit from Work
}

\subsection{Introduction}

Labour-supply arguments have established discursive supremacy in the public debate on pensions and retirement (Marschallek 2004). Since the World Bank averted the "old age crisis" (The World Bank 1994), the looming process of population aging has made cost efficiency the main priority among policy makers. By contrast, the status quo in academic retirement literature has been characterised by more balance, as rational-choice pull approaches are challenged by firm-based push approaches (Kohli \& Rein 1991). While the former largely consider monetary incentives responsible for early exit from work, the latter highlight the role of structural constraints as evidenced by high unemployment and a relevant percentage of retirees who leave the labour market because of health problems.

With the aim of outlining the appropriate theoretical bases for the later empirical analyses, this review compiles arguments from different strands of research and different disciplinary perspectives that contribute to a fuller understanding of the multifaceted work-retirement nexus. The next section of this chapter makes clear the theoretical foundations underpinning laboursupply approaches to retirement behaviour and reviews the corresponding standard econometric models. The third section explores arguments that relate retirement directly to health status and productivity changes that accompany the process of aging. A similar line of reasoning is used in human capital models, which by reference to implicit contracting uncover the origins of employers' high propensity to shed older workers.

Subsequently, I shall present sociological perspectives on retirement. Inter alia, they propose the need to historicise retirement as a normative status configuration in modern societies. The life course approach leads the way towards a dynamic concept of retirement, which is understood as an institutionally embedded life course event. Further, it sheds light on "linked lives" in retirement timing. In the fifth section, I consider the popular welfare-regime approach, which has seen frequent use in retirement research. Despite a lack of analytical rigour, the welfare-regime approach is portrayed as a potent heuristic tool for the classification of internationally diverse social systems of welfare production.

In the course of this literature review, I discuss the analytical strengths and weaknesses of each of the approaches with respect to my research question and highlight eventual conceptual shortcomings. It shall be noted in advance that the proposed categorisation does not always draw clear-cut boundaries between rival theories. In fact, many of the cited studies embrace some sort 
of cross-over approach, and there is a noteworthy tendency towards an interdisciplinary exchange in the field of retirement research. To give an example, social scientists increasingly pay heed to rational choice arguments in their studies instead of discarding them a priori as ontologically flawed (Szydlik \& Ernst 1996). Conversely, some mainstream economists have recognised that involuntary retirement is not adequately captured by standard life-cycle models (Herbertsson 2001; Börsch-Supan \& Jürges 2006). Nonetheless, it is straightforward to discern certain centers of gravity in the theoretical accounts used by different research traditions.

\subsection{Labour-Supply Theory}

According to economic labour-supply theory, individual workers make their retirement decisions by maximising their utility. While earlier static models saw the retirement decision merely as a non-recurrent allocation of time between the employment and post-employment phase, state-of-the-art dynamic life-cycle models treat the transition to retirement as a discrete inter-temporal optimisation problem (Burtless \& Moffitt 1984; Lazear 1986; Arnds \& Bonin 2003). The bottom line is that elderly workers face a fundamental trade-off between the consumption of goods, which require the earning of an income through paid work, on the one side, and the consumption of leisure in retirement on the other. In a sequential decision process, the worker accordingly chooses his or her labour supply as a function of his or her income prospects. Not only are incentives dependent on expected wage earnings but also on present and future pension entitlements.

The standard model in this literature is the option-value model (Stock \& Wise 1990). Each worker accordingly compares the expected future utility streams that would result from retiring immediately and from remaining employed for another year, respectively. The option value is the utility compensation for working one additional year. This financial premium for continued work is composed of wage earnings on the one hand and the increase in the discounted value of expected social-security benefits - the so-called social-security wealth - on the other. Given that people differ in their valuations of these financial prospects, the optimal moment to retire, in principle, also varies with a person's impatience, risk aversion, and preference for work versus leisure. If the option value is positive, workers can achieve a utility gain by postponing retirement. Otherwise, the optimal choice is to retire.

From this point of view, early retirement is driven by adverse incentives produced by the pension system and other social-security programmes. Numerous econometric studies provide empirical support for the strong effect of monetary incentives on retirement decisions (Blöndal \& Scarpetta 1998; Casey et al. 2003; OECD 2006a; Schils 2006). Two edited volumes, which form 
part of a project by the National Bureau of Economic Research (NBER), merit closer attention as they figure prominently in the economic literature. Jonathan Gruber, David Wise, and collabourators investigate through systematic country comparison how national social-security provisions influence retirement incentives by imposing implicit taxes on work (Gruber \& Wise 1999a, 2004a). In this way, the authors draw attention to interesting empirical regularities such as the sharp rise in retirement rates at ages of first eligibility for benefits and the employment effects of changes in pension plans.

Existing social-security programmes are benchmarked against a hypothetical incentive-neutral system, in which benefits are adjusted purely on the basis of actuarial standards. It is shown that the thus-defined "tax penalty on work" (Gruber \& Wise 1999b) varies noticeably between countries. Following cross-country estimations of potential reform scenarios, the percentage of economically inactive men in "early exit countries" like Germany or the Netherlands would diminish radically as a consequence of a unified reform that introduces an actuarially-fair system (Gruber \& Wise 2004b: 30 f.). The rates of labour market participation of elderly workers in other countries would not be altered considerably. Considerably more similar are the results for the eventual implementation of a three-year delay in eligibility ages. Such a tightening of the eligibility criteria of retirement benefits would yield a reduction in the proportion of economically inactive men of the relevant age between 23 and 36\% (ibid.: 35).

Based on such projections economic studies in unison advise policy-makers to remove early retirement incentives, which are seen as barriers to the labour market participation of older people. This conviction originates from the economic credo that low employment participation equals a loss of welfare. Put bluntly, "such distortions of labor-leisure decisions are problematic as they reduce labor supply, output and living standards" (OECD 2002b). This reasoning leads to the view that "all fiscal subsidies to early retirement should be phased out" (Koning et al. 2004: 43).

To sum up, exploiting the power of formal analysis, labour-supply theory has forcefully established the linkage between benefit generosity and early retirement. The resulting evidence clearly demonstrates the responsiveness of individual actors to monetary incentives, even though the magnitude of this elasticity is unknown. Economics also has the merit of emphasising that retirement decisions are characterised by essential uncertainty. In this vein, retirement has been called "an individual-specific 'experience good' [...], about which one knows virtually nothing until one tries it. Then, people might choose to become retired, only to discover that it lowers well being" (Charles 2002: 16).

Then again, micro-economic models have often been criticised for treating retirement as a free decision, neglecting the importance of structural constraints for the timing of labour market withdrawal. Before the assumption of voluntary 
choice is problematised in the next section, I would like to put forward a different objection, namely that individual and cultural differences tend to be neglected in econometric models of retirement.

Life-cycle models are mostly characterised by an across-the-board handling of individual heterogeneity and socio-cultural differences (Legros 2006). As the incentives represented by social benefits are the main explanans in the optionvalue model and others like it, preference parameters are normally estimated uniformly for the entire sample. This is a matter of choice and convenience as, in principle, the econometric apparatus would allow for the introduction of heterogeneous preferences. This is rarely done however, ${ }^{3}$ because "in many countries, it is likely easier to identify the effect of incentive measures than the effect of wealth levels" (Gruber \& Wise 2004b: 16). Another reason to ignore heterogeneity in work orientations and preferences is related to the intention to "accurately isolate the program incentive effect" (ibid.: 12). Since common proxies of preference parameters - such as wage, occupation or education - also in part determine the value of the incentive variable, many economists prefer to estimate their models without these indicators. The (untested) justification for this procedure is that "much of the estimated effect of these variables is likely to reflect the influence of financial incentives and not individual heterogeneity" (ibid.).

Critically, taking account of varying preferences would render empirical findings less straightforward. It would then become more complicated to derive clear-cut policy implications from such more complex models. In order to avoid undesired ambiguities, the standard econometric model of retirement behaviour therefore operates on the basis of the unrealistic assumption that work orientations do not vary across individuals, hence attributing diverse retirement timing solely to pecuniary incentives.

Nevertheless, the NBER study provides a rich empirical picture of retirement behavior. As for social inequality, it is noteworthy that social-security wealth - a good proxy of life-time earnings - in most countries has a positive effect on retirement probabilities (Gruber \& Wise 2004b: 16). This implies that high entitlements to social-security benefits, which are usually the result of either long working histories or high wages, tend go along with a higher propensity to retire early. With regard to culture, Gruber and Wise (2004b: 17) claim that "the results point to an important relationship between incentive effects and labor force participation, independent of cultural differences among countries." Yet, this can be regarded as an exaggerated conclusion from the presented results, given that the authors also report that the incentive variable is not significant or

3 For a remarkable exception, see Gørtz (2006). 
even of the "wrong" sign in Spain and Italy - the two Mediterranean countries in their twelve-country sample. This is not to claim that monetary incentives do not operate in Southern Europe; but it should be kept in mind that the available empirical evidence is more ambiguous than suggested by the economic mainstream.

\subsection{Productivity, Human Capital, and Aging}

A seemingly simple explanation for retirement timing is a decline in the ability to work of aging workers. Naturally, physical condition tends to deteriorate with age, and a significant lowering in fitness levels obviously affects the capacity to work. Correspondingly, disability is universally recognised as one of the most frequent reasons for retirement (cf. Blekesaune $\&$ Solem 2005). A radical interpretation of the negative correlation between age and health consist in the so-called "deficiency hypothesis of aging," which suggests an inevitable, rapid decay of the physical and mental fitness of elderly workers. If older workers are not productive enough, it would be only logical that employers try to push them into early retirement.

However, the discussion on the relationship between aging and productivity has shown that the age-related decline in productive abilities is by no means a linear or deterministic process. Gerontologists have forcefully criticised the "deficiency model of aging" as outdated and mechanical (Clemens et al. 2003: $56 \mathrm{f}$.), arguing that aging is accompanied by a structural change in work capacities rather than by a loss of them. While young workers usually are physically stronger and better at some cognitive skills, like creativity or flexibility, elderly workers are generally more reliable and have a superior job knowledge (Börsch-Supan et al. 2009b). ${ }^{4}$

There have been numerous attempts to measure age-productivity curves accurately. The typical representation of this relationship is in the form of an inverse U-shape (Fehr 2009), where productivity initially increases with ongoing formal education and on-the-job training and then declines after some age threshold (OECD 1998; Fehr 2009). However, no one knows with precision whether this turning point really exists or where it lies. Obviously, for the design of public policies, it makes a substantial difference whether the average productivity of workers falls after age 45 or after age 60 (Börsch-Supan et al. 2009a).

4 For example, Brumfield (2008) reports findings that suggest that older scientists are more productive than their junior counterparts. Accordingly, professors in their 50 s and 60 s publish far more papers each year than those in their early 30 s while being as well cited and respected. 
Empirically, the observed shape of age-wage curves seems to underpin the hypothesis of curvilinear productivity functions (OECD 1998). However, a dedicated OECD study also found that variations within an age group exceed the average differences between age groups. It concludes that "the productivity potential of the older work groups does not appear to be substantially impaired by age per se" (OECD 1998: 136, 138; emphasis in original). In any case, since they are based on cross-sectional data, such generalisations do not take account of cohort differences. Moreover, this and similar economic studies assume that wage differentials directly reflect productivity differentials (Fehr 2009). In all likelihood, this is wrong; not only are wages co-determined by institutional regulation but also employers may be guided by erroneous prejudices concerning the productivity of elderly workers.

Hence, hard evidence on productivity is difficult to gather. Surveys among employers often show that elderly workers are not perceived as less productive than their younger colleagues (Koller 2001: 480-490; Brussig 2005: 7-9). However, the measurement of work performance over the life course is particularly sensitive to the instruments applied (Skirbekk 2003: 19). Summarising findings based on more objective methods like work-sample tests, Skirbekk (2003) reaffirms that productivity probably follows an inverted U-shape with increasing age. Arguably, a significant decline normally occurs at around 50 years of age, when cognitive abilities start to deteriorate. Despite rising job experience, a threshold effect prevents productivity from improving significantly further: job expertise does not seem to increase beyond a certain ceiling.

However, the reliability of such "laboratory" experiments is doubtful provided that most real-world work tasks are conducted not by isolated individuals but by teams of workers with a specific internal allocation of roles (Börsch-Supan et al. 2009b). Individual work performances are actually to a large degree interdependent. Therefore, one underlying problem of this entire debate is that productivity is not a purely individual characteristic that could be appropriately conceptualised as the sum of physical and mental skills (Werding 2008: 5-6). Instead, development of working capacities over the life course is highly context dependent. For instance, the productivity of elderly workers varies crucially in function of occupation and work conditions. In this vein, the gerontological research tradition stresses the fact that health problems causing workers' exit from the labour market can often be avoided by creating an appropriate work environment.

Moreover, productivity also depends on how work is organised. Since modern societies are characterised by an increasing division of labour, the productivity of an individual always depends on the size and composition of work teams as well as on the technology employed. As Börsch-Supan et al. (2009b) emphasise, productivity should therefore be conceptualised at the level of firms, industries, or national economies rather than at the personal level. In this vein, Werding 
(2008) builds on a large-scale macro-data panel to assess the age-productivity nexus in a comparative fashion. His results support the conventional view that demographic factors influence workforce productivity. The estimated curvilinear effect is even stronger than usual, with total factor productivity peaking strongly for the group of 40-49 year olds. However, the author admits that as there are several plausible micro-level mechanisms that could explain this empirical pattern at the macro level, there is no consistent proof of an age-related productivity decline.

Seniority wages - i.e. age-related wage increases that are not backed by increases in work performance - are often mentioned as a factor that aggravates the supposed productivity deficit of elderly workers. Contrary to perceived wisdom, however, the above-mentioned OECD study shows that it is not the oldest employees that have the highest earnings. Instead, age-specific wage curves peak for the age-group of 45-54 years in all of the 20 countries under observation, with the single exception of France (OECD 1998). Compared to these prime-aged employees, workers aged 55-64 years had gross earnings that were on average $9 \%$ lower. To be detrimental to employment participation, the true average productivity deficit of elderly workers would need to exceed this already substantial decline. Regardless, these numbers have to be interpreted with caution because of unobserved cohort effects.

There are further reasons why a cross-sectional view on wages and productivity is most probably flawed and why a life-cycle perspective seems indispensable. As Lazear's (1979) implicit contract model shows, seniority wage structures can, in fact, be in the interest of both employers and employees. A wage profile that pays workers less when they are young and more when they are old enhances workers' motivations. In this way, a combination of large amounts of effort and high life-time wages can be achieved via an implicit long-term employment contract. Interestingly, this solution outperforms the alternative equilibrium of less effort and low wages (Lazear 1979: 1264). "Back-loaded compensation" seems to be a beneficial arrangement for firms as well as for workers (ibid.: 1283), especially if the latter are risk averse and consequentially prefer longterm employment (Hutchens 1999). However, steep wage paths also make early retirement particularly attractive for firms. When workers reach the normal retirement age, employers can exploit legal provisions of mandatory retirement as part of the implicit contract.

Another central determining factor for the development of productivity over the life course is training and education. As highlighted by the human capital perspective (Mincer 1993), productivity levels are strongly influenced by skills investments in the past. Steadily diminishing human capital can then be considered a main reason for early retirement: "Because knowledge of older technologies becomes obsolete and because people forget, human capital is subject to depreciation" (Alders 2002: 2). The latter can be avoided 
by engagement in further training. Yet the amortisation periods for skill investments, for both employers and employees, decrease with increasing age (Szydlik \& Ernst 1996). The human capital approach explains how this pattern results in a downward spiral in retirement ages once early exit has become the expected norm (Ebbinghaus 2001: 88). As the expectations of firms and workers regarding the timing of retirement are crucial determinants of the amount of human capital investments (Alders 2002), the trend to early retirement turns into a self-reinforcing process.

The human capital approach to early retirement has become more relevant in recent decades, as Western economies have gone through an era of deep structural transformation. The shift in the production process implies an accelerated rate of technological change that is especially to the disadvantage of elderly workers, whose qualifications increasingly become quickly outdated (Buchholz et al. 2006: 7). To prevent this, workers depend on firms' willingness to support lifelong learning. Moreover, as already mentioned above, productivity is not simply the result of health and skills investments but hinges on the organisation of work as well. Successful aging thus also depends on employers providing an adequate work environment for their older employees.

To sum up, the available evidence on the productivity of older workers is inconclusive. Although it is commonly assumed that cognitive and physical skills decrease after a certain age, there is no robust scientific evidence to prove this assumption. Nevertheless, productivity-based approaches provide a rich picture of the sources of the disadvantage of elderly workers in times of structural economic change. They allow the researcher to address differences between firms with regard to work strain, further training, and the replacement rate of the workforce.

Overall, however, productivity-based explanations of individual behaviour represent an equation with too many unknown parameters. Therefore, human capital theory, like other productivity-based explanations, is not capable of explaining individual retirement dynamics in a satisfactory manner. Moreover, an account of heterogeneous preferences is painfully absent in the human capital approach to retirement. The underlying assumption is that workers generally want to keep on working because steep wage paths represent an incentive to stay employed. In this way, employers ultimately determine the time for the retirement of employees, who themselves would rather stay on the job. This logic runs counter to survey evidence showing a wide-spread disposition towards early retirement (Esser 2005b; cf. chap. 4). To adequately account for social heterogeneity in retirement the individual worker needs to be placed at the center of the analysis. 


\subsection{The Sociology of Retirement and the Life Course Perspective}

Since Weber's inquiry into the religious roots of modern work-ethics, sociology characteristically sees work as a source of identity and self-realisation. In sociological theory, the meaning of retirement has therefore been inseparably linked with a normative dimension (Kohli 1986; Grint 2005). In Marxist thought, the idea that meaningful work is essential to human self-realisation is central, too (Elster 1986; cf. section 3.1.1). In sociological approaches, retirement is thus regarded as a particular social status that is inherently tied to one's working life. The implied emphasis on an intrinsic value of work is in sharp conflict with the economic concept of a work-leisure trade-off that is mainly mediated in monetary terms.

Sociologists have also been concerned with the historicisation of retirement as a modern phenomenon and the corresponding change of its social meaning (Kohli 1985; Morrison 1986; Ehmer 1990; Abbott 2005; Hudson 2005). Indeed, a post-working life of considerable duration is a rather recent phenomenon. In the nineteenth century, the majority of the population did not live to see the age of 65 , and those that did were normally still working. For example, Kohli (1985: 10) reports that $79 \%$ of men aged between 60 and 70 years in Germany in 1895 were still working. Comparable estimates for the situation in the U.S.A. show that approximately $69 \%$ of American men over 65 were still in the labour force in 1900 (Abbott 2005: 314). For men in the same age group, Moen and Gratton (1999) still report a share of 38\% for the years 1935-36, in the heart of the Great Depression. In short, before the $20^{\text {th }}$ century, retirement was not a distinct phase of life.

The establishment of retirement as an experience that is universally expected by everyone was grounded on two historic innovations: a decline in mortality and morbidity on the one hand and the erection of a public pension system, which provides universal access to income in old age, on the other. Together with the generalisation of compulsory schooling, these features of modernisation have resulted in the establishment of a relatively standardised biography after the Second World War. Only since then has the normal life cycle been divided into the preparatory phase of education, the central phase of economic activity, and the post-work phase of retirement (Kohli 1985).

Furthermore, retirement has not been associated with a time of "fun and selfindulgence" (Ekerdt 2004: 8) from its conception. Instead, retirement was until quite recently often accompanied by physical malady or "structured dependency" (Townsend 1981). Only as a result of major improvements in the health and income situation of older people during the post-war period has retirement become a state of "late freedom" (Rosenmayr 1983). Characteristically, this "third age" offers chances for self-fulfillment in a life phase without work (Laslett 1991). 
Many recent sociological studies on retirement can be placed within the life course paradigm. The life course perspective stresses the institutional embeddedness of the temporal patterning of individual biographies (Elder 1995; Marshall \& Mueller 2002; Mayer 2009). According to Martin Kohli (1985), the institutionalisation of the life course consists of the establishment of a biographic programme that structures the chronological order of life histories. ${ }^{5}$ In this way, the employment-centered tripartition of life sequences sets a generalised schedule for labour market participation in individual biographies. The theorem of the institutionalised life course suggests a substantial degree of homogeneity in the temporal order of life events, albeit not uniformity. The diversity of possible life trajectories notwithstanding, the overarching institutional framework systematically shapes individual biographies by imposing a specific chronological opportunity structure (Kohli 1985, 2003). ${ }^{6}$

Another central element within the sociology of retirement is the notion of norms of aging. According to life course theory, retirement behaviour is significantly influenced by age-graded social norms (Settersten \& Hagestad 1996; Han \& Moen 1999; Settersten 2003). In the pioneering study of Neugarten, Moore, and Lowe (1965: 711), age norms are conceptualised as a set of social expectations that add up to "a prescriptive timetable for the organization of major life events." Age-related social expectations can also emerge as a side-product of other norms directed at the use of time and the duration of particular spells in biographies (Scherger 2007: chap. 5). Arguably, there exists a high degree of implicit societal consensus in the attitudes towards age-appropriate behaviour, not only with respect to labour market transitions but also with respect to major family events (Mortimer et al. 2005). Furthermore, the institutionalisation of the life course as a regulatory system has given rise to a high awareness of actors regarding their own timing with regard to the "social

5 Some scholars have questioned the status of the life course as an institution (cf. Scherger 2007). Notably, Karl-Ulrich Mayer (1996: 48) posits that patterns of age differentiation are, in fact, largely epiphenomena of institutional effects on multiple life domains (work, family, etc.). While this may be true, it brings up the question of how specific institutional age thresholds come into existence in the first place, turning the controversy into a "chicken and the egg" question. Moreover, the efficacy of institutional regulation does not rule out the existence of the life course as an overarching normative institution that serves as a guideline for individual actors and institutional gatekeepers. I will return to the question of age norms as manifestations of the institutionalised life course in the fourth chapter.

6 In opposition to Kohli's account, others have stressed the counter-movement of a deinstitutionalisation (or de-standardisation) of the life course, which has arguably taken place in recent decades (cf. George 1993; Guillemard \& Rein 1993). Despite an increasing pluralisation of life-course patterns, the degree of heterogeneity in the timing of key life events is still rather limited. For details on the de-standardisation debate, see Scherger (2007). 
clock" (Moen et al. 2005). After all, assumptions about the salience of norms of aging are very widespread among life course scholars (Settersten \& Mayer 1997: 242). Such assumptions are also manifest in the debate on "agism," which has highlighted the persistence of negative stereotypes about older workers (McGregor \& Gray 2002; Bytheway 2005).

The concepts of the institutionalised life course and concomitant age norms are closely related to the notion of moral economy, which was introduced by the historian E.P. Thompson. It has been evoked to maintain that people's attitudes towards social institutions are irreducible to a purely self-interested perspective (Kohli 1987; Mau 2002; Svallfors 2006). Instead, people's attitudes towards work and the welfare state are loaded with norms of reciprocity and fairness that are formed under the influence of social policies. According to this "cultural institutionalist" view, "institutions create or socially construct the actors' identities, belongings, definitions of reality and shared meanings" (Rothstein $\&$ Steinmo 2002). Hence, the members of a socio-political community develop a particular sense of moral responsibility, which responds to the signals of welfare and labour market policies. The moral economy also offers a rich reservoir of ideas that can be drawn upon by social actors to achieve (or redefine) their interests (Blyth 2002).

The life course paradigm is furthermore characterised by an elective affinity towards a reflexive approach to social theory (Giddens 1997). In this vein, the institutionalised life course is constituted and reproduced through the mutual interplay among the triad of formal institutions, biographical agency, and normative expectations. Accordingly, the societal life course regime affects individual biographies by means of selective incentives and constraints embedded in various socio-economic institutions (Settersten \& Mayer 1997; Leisering et al. 2001; Geissler 2004). Age-related rules and regulations are present in a whole range of state arrangements, like welfare benefits and labour market regulations as well as education, training systems, and taxation (Lynch 2001). Institutional opportunity structures communicate age-specific social expectations to individual actors (Behrens \& Voges 1996). By this token, the configuration of social-security programmes gains normative significance. Institutionalised age norms can also be detected in collective agreements between the social partners, firms' retirement plans, and employer-employee relationships, which are loaded with long-term reciprocal expectations (Kohli 1987; Streeck 1992).

At the micro level, the life course approach stresses the "path-dependent" dynamics of individual biographies. Arguably, early life events often exert an influence on later-life events (Mayer 2009). For instance, early career trajectories modify workers' opportunity structure for subsequent life course transitions. Family formation can similarly produce long-run "biographical pacing" (Han \& Moen 1999) effects on successive biographical transitions, including retirement. 
Social clocks move at different rates for men and women (Han \& Moen 1999). However, the retirement behaviour of women is still under investigated. Age, cohort, and period effects have been particularly difficult to discern in the wake of increasing female labour market participation. In fact, today's retired women in most European countries belong to a generation for which life-long employment was the exception rather than the rule (Brugiavini $\&$ Peracchi 2005). While the female life course is supposedly less institutionalised overall, family effects are arguably of special salience for women. As we shall see in detail in section 3.4, the life course tenet of "linked lives" establishes the relevance of the household context and pinpoints the interdependence of spouses' retirement trajectories.

Another hotly debated issue in the literature - especially in gerontology has been the limits of individual decision-making (Higgs et al. 2003; Hyde et al. 2004; Phillipson \& Smith 2005; Riach \& Loretto 2009). Stressing the role of structural constraints, this view is formulated in direct opposition to the labour-supply approach (Vickerstaff \& Cox 2005). Here, retirement is treated as externally imposed on elderly workers who have no chance to get another job, or are in poor health. Individual choice requires some discretion. Since the employment opportunities of elderly workers are slim, the argument goes, unemployment at later ages often amounts to forced retirement (Hirsch 2003). Arguably, instrumental cost-benefit considerations are not in effect in the case of involuntary retirement. A misleading version of this argument implicitly assumes that workers cannot (or should not) accept lower wages, hence neglecting that a lesser-paying job could be a viable alternative to early retirement.

Recent related work has livened up the earlier discussion about the subjective perceptions of the retirement event (cf. Atchley 1976). It could be shown for the U.S. that people who lack choice perceive their retirement as involuntary and externally imposed (Szinovacz \& Davey 2005). Interestingly, the topic has seen growing interest in economics as well, as research on the impact of retirement on personal well-being confirms the importance of individual control (Charles 2002; Szinovacz \& Davey 2004; Börsch-Supan \& Jürges 2006; Dave et al. 2006). There is a broad consensus that retirement is more enjoyable if it is voluntarily chosen (Shultz et al. 1998; Kim \& Moen 2002; Bender 2004). Vice versa, forced retirement frequently leads to low subjective well-being or to depression. Nevertheless, it is far from unanimous whether the retirement experience itself accounts for differences in quality of life in old age or if the latter reflect inequalities in employment biographies (Hyde et al. 2004).

In sum, sociological approaches to retirement trace the emergence of age norms back to historical developments in age-specific policies and institutional arrangements. Moreover, the life course perspective accounts for the formation 
of preferences through divergent life histories. In principle, the life course approach is, hence, particularly well-suited to addressing social heterogeneity in the timing of retirement. However, the circular structure of some arguments inspired by reflexive social theory is at odds with the ambition to test these hypotheses empirically. ${ }^{7}$ In addition, the life course approach rests on an eclectic set of theorems which do not in every respect add up to a consistent theory (cf. Mayer 2009). For instance, it remains unclear whether age norms should be seen as societal constraints on individual decision-making or rather as an integrative element of actors' preferences. Frequently, retirement-related analyses in the life course tradition implicitly or explicitly borrow from rational choice pull approaches and from firm-based push approaches alike, giving rise to undesirable ambiguities.

A key conceptual weakness of the life course paradigm lies in the unsystematic treatment of structural constraints. The focus on societal norms and institutions has largely hindered life course scholars from explicitly modelling the limitations to individual agency. Although not being linked directly to the question of retirement timing, this problem is taken up in the debate on involuntary exit from work. Consistent with qualitative and quantitative findings about retirement planning and the psychological adaptation to retirement, this literature emphasises the individual experience of this status passage. However, the phenomenon of forced retirement is not systematically linked to an account of social inequalities that could explain the unequal distribution of retirement opportunities. In the third chapter, I shall thus propose an analytic framework for the study of retirement behaviour that utilises the life course perspective as well as, by drawing on a socialstratification account, integrating social-class differences into the theoretical model.

7 The theoretical relationship between individual behaviour, formal institutions, and socio-cultural norms is rarely spelled out unambiguously. In a prime example of scholarly vagueness, Leisering et al. (2001: 16 f.) state that the diminishing share of formal employment contracts has induced "frictions between institutional normality prescriptions and individual biographies, which require mutual legitimisation through cultural patterns and increasing individual acceptance" (ibid.: 16). The authors go on to argue that these frictions, which arise from the interaction between individuals and institutions, are stimulants of change. They conclude that all this leads to a changing significance of institutionalised life course regimes as well as of their contents. ["Reibungen zwischen individuellen Normalbiographien und institutionellen Normalitätsunterstellungen sind entstanden, die wechselseitig ihre Legitimation aus kulturellen Mustern und individuellem Zuwachs on Akzeptanz beziehen. Diese Reibungen sind Stimulantien des Wandels. Sie werden sozial wirksam durch die Interaktion zwischen Individuen und Institutionen. Insgesamt ergibt sich daraus ebenso ein Wandel der Bedeutsamkeit institutionalisierter Lebenslaufregime wie deren Inhalte."] 


\subsection{Welfare Regimes and Early Retirement}

In Esping-Andersen's seminal work The Three Worlds of Welfare Capitalism, welfare-state regimes are defined as "qualitatively different arrangements between state, market, and the family" (Esping-Andersen 1990: 26). Accordingly, each regime is associated with a distinct mode of state intervention into the market sphere, which is systematically intertwined with particular labour market and family structures. Building on earlier work by Titmuss (1974), national packages of social policies and labour market regulations are delineated by the resulting degree of "de-commodification of labour," i.e. the extent to which "social citizenship" (Marshall 2000 [1950]) is guaranteed independent of market income.

The original threefold-regime approach distinguishes between a socialdemocratic, a conservative, and a liberal welfare regime (Esping-Andersen 1990). The social-democratic (or universal) regime provides universal rights of social citizenship and extensive social services. Furthermore, this kind of welfare state is characterised by its strong commitment to a full-employment policy and the engagement in far-reaching income redistribution aiming at social cohesion, financed through heavy taxation. In a conservative (or corporatist) welfare regime, the dominant Bismarckian social-insurance system ties eligibility for social benefits closely to employment. The guiding principle of subsidiarity promotes the traditional male bread-winner model (e.g. through the taxation system). While it has been quite successful in maintaining a fair standard of social security, the conservative welfare state tends to reproduce structures of social stratification along occupational categories. In contrast, in a liberal (or residual) welfare regime, the state limits itself to preventing extreme poverty, following a "principle of non-interference." As far as possible, the liberal regime relies on the aggregate welfare-enhancing effects of market self-regulation and high employment rates, with this pattern produces high levels of poverty and social inequality.

In the aftermath of the Three Worlds study, several authors proposed to extend the welfare-regime typology, sacrificing simplicity for accuracy. In particular, the inclusion of a fragmented welfare regime as a distinct type has become a standard in the literature (Arts \& Gelissen 2002). Specifically, the Mediterranean welfare states, with Italy as the paradigm case, are characterised by dualist labour markets and a highly polarised character of social protection, including clientelistic welfare policies and a pronounced gender gap. Unlike conservative welfare states, the Southern model of welfare provides national health services on a universalistic basis (Ferrera 1996). In addition, the introduction of a "Radical" regime, which demarcates the "Antipodean" welfare states of Australia and New Zealand from their liberal Anglo-Saxon counterparts, has seen some support (Bambra 2007). Further, the "Japanese familialist residual welfare regime" has 
been proposed as a stand-alone type (Ebbinghaus 2006a: 73). Although the course of Eastern European welfare states may be not entirely clear yet, Bukodi and Róbert (2007) suggest distinguishing between a "post-socialist liberal" regime (with the Baltic states) and a "post-socialist conservative" regime (with the Czech Republic, Hungary, Poland, Slovenia, and Slovakia).

Welfare-state theory assumes a close relationship between welfare regimes and the incidence of early retirement (Esping-Andersen 1996b), because the political responses of national economies to deindustrialisation since the 1970 s were "intimately related to the nature of their welfare state" (EspingAndersen 1996a: 10). Specifically, Esping-Andersen (1990: 152) argues that the welfare state influences the timing of retirement through a combination of labour-supply and labour-demand effects. Accordingly, the regime-specific type of welfare-state intervention determines national retirement patterns by offering a specific "menu of alternative income maintenance choices" (EspingAndersen \& Sonnberger 1989: 15) on the one hand, and by altering employment opportunities on the other hand (Esping-Andersen 1996b).

In detail, the salience of early retirement in continental Europe is seen as the result of high levels of long-term unemployment among older workers in combination with generous pension benefits, a genuine product of conservative welfare-state intervention (Guillemard 2001). Early retirement has long been explicitly promoted as a means of creating employment opportunities for the young. ${ }^{8}$ In Scandinavian countries, conversely, low early exit rates are achieved by maintaining favorable labour market conditions for elderly workers via active labour market policies. Despite the overall generosity of old-age pension benefits put in place by the universalist welfare state, there are relatively few institutionalised early retirement incentives. ${ }^{9}$ In liberal welfare-state regimes, exemplified by the Anglo-Saxon countries, relatively high employment rates of elderly workers are maintained by providing few early retirement incentives and by keeping the unemployment rate down on low-wage labour markets.

Paraphrasing Esping-Andersen, the patterns of retirement are influenced by the welfare state in two essential ways. Firstly, the generosity of the pension system (and other systems of social security) has a direct effect on the labour supply of elderly workers. Secondly, the welfare state has an indirect effect on the work-retirement nexus, because it shapes labour market structures, which

8 Yet the underlying assumption that the amount of work to be done is fixed - the socalled "lump-of-labour fallacy" (Koning et al. 2004: 43) - was misleading. The eventual effect of early retirement policies on the unemployment rate remained small at best.

9 Pension system can simultaneously provide high replacement rates at the statutory retirement age and punish early retirement by means of high discount rates. 
in turn alter the extent of early retirement through demand side effects. ${ }^{10}$ In synthesis, the expected result is a clustering of cross-national patterns of retirement behaviour along the lines of welfare-state regimes (Esping-Andersen 1990: 144). The employment rate (and even more so the employment rate of the elderly, young, or women) should describe a U-shaped function of the degree of decommodification: both a high (social-democratic) and a low (liberal) degree of decommodification are compatible with high labour market participation of the elderly; medium levels of welfare-state interference in conservative (and fragmented) regimes conversely lead to low retirement ages.

In this vein, many scholars have studied the impact of the welfare state on employment rates in general (Scharpf \& Schmidt 2000; Scharpf 2001; Furåker 2003; Heidenreich 2004), and on early retirement in particular (Esser 2005a; Blossfeld et al. 2006; Ebbinghaus 2006a; Kim 2009). Extending the regime approach, Ebbinghaus (2006a: chap. 3) identifies five clusters of "institutional affinities" covering the realms of the welfare state, the system of economic governance (or production regime), and the system of industrial relations. Each of these macro constellations gives rise to a distinct employment regime with particular consequences for early exit from work. Ebbinghaus's comparison of ten OECD countries confirms the "protection pull hypothesis," insofar as higher pension levels generally go hand in hand with rising early retirement. Another comparative study addressing the impact of globalisation on late careers in twelve countries also adopts a welfare-regime approach (Buchholz et al. 2006). By and large, its findings support the hypothesis that the effects of economic transformation on the patterns of retirement vary according to the national "institutional filters," broadly following the predictions of Esping-Andersen described above (Hofäcker et al. 2006). In order to systematically compare typical life course patterns, including the transition to retirement, across countries, Karl Ulrich Mayer (2001) proposes a fourfold typology of "life course regimes," which correspond to the expanded welfare-regime typology including Southern Europe. Somewhat similar is the approach used in Lessenich (1995), who stresses the distinctive age orientation of welfare regimes.

After the publication of The Three Worlds of Welfare Capitalism, many studies have been concerned with arriving at an accurate country ordering (Arts \& Gelissen 2002). In the intense debate, Esping-Andersen's typology has received

\footnotetext{
10 On closer inspection, however, labour-market push factors appear to be of greater importance to Esping-Andersen than the pension system, because low unemployment is implicitly treated as a necessary condition for retaining elderly workers in the labour force. If the labour market does not offer older workers chances for employment, the argument goes, national economies are likely to display high rates of early exit although they may offer only mediocre benefits (Esping-Andersen \& Sonnberger 1989).
} 
substantial criticism, most of which addresses its tendency to oversimplification. The empirical reality often appears to be far more diverse than the regime approach suggests. Notwithstanding the fundamental trade-off between parsimony and accuracy, it is noteworthy that some of the more refined typologies work significantly better than the original three-worlds approach when it comes to clustering countries with respect to central empirical dimensions of "welfare statism," such as social spending and its sources of finance (Bambra 2007). Welfare regimes have proven most fruitful when used "primarily as pragmatic conceptual devices for comparison" (Ebbinghaus \& Manow 2001: 9).

A second line of criticism concerns the role of women and the family in the regime approach. Feminist scholars have described the approach as genderblind. Firstly, regime types have been shown empirically not to fit cross-national patterns of women's employment or social-care services very well (cf. Sainsbury 1994; Antonnen \& Sipilä 1996; Daly 2000; Lewis 2006; Lewis et al. 2008). Secondly, and more importantly, the concept of de-commodification has been found to be inappropriate because it does not take into consideration to what extent the formal criteria for social rights are gender linked (O'Connor 1993: 511; Orloff 1993: 319). Instead, the gender dimension is largely subsumed under the class dimension of social stratification. Put bluntly, "the worker Esping-Andersen has in mind is male" (Lewis 1993: 14). Arguably, due to this shortcoming, the conventional regime approach not only neglects important ways in which state policies affect gender relations but is also unable to deal with the question of gendered political interests (O'Connor et al. 1999: chap 1). Alternatively, it has been proposed to distinguish social policy regimes on the basis of their degree of "familialism," or how much they support the traditional "male bread-winner model" (Lewis 1993; Pascall \& Lewis 2004; Leitner 2005). The feminist critique furthermore objects that the regime framework fails to appreciate genderrelated inequality of condition, especially with regard to women's unpaid caring and domestic work (Orloff 1996):

"A gender sensitive analysis of welfare state regimes entails not only an examination of benefits and services in terms of gender stratification effects but also a focus on the way in which productive and reproductive activities are articulated" (O'Connor 1993: 514).

Esping-Andersen (1999: chap. 4) has responded to these criticisms by readjusting the role of family and household work in his framework. In this modified account, one distinctive feature of regimes is the relative contribution of the family to a country's welfare mix. Accordingly, the extent to which the welfare state relies on private households to absorb social risks defines its degree of "de-familialisation". The key criterion of de-familialisation is the degree of compatibility between motherhood and employment careers (Esping- 
Andersen 1999: 51). By this token, the social-democratic welfare regime cluster clearly constitutes the most family-friendly institutional environment.

Given the focus of the present study, it is useful to consider how the Mediterranean countries rate with respect to de-familialisation in comparison with the rest of continental Europe. It turns out that Southern Europe exhibits very low levels of coverage of childcare and home-help provided to the elderly (Esping-Andersen 1999: 61). The latter dimension is of particular interest here because early retirement can be seen as a way of becoming available for caring (I will return to this point in section 3.1.4). Here, the Southern European countries not only stand out for their low levels of help services provided for the elderly population but also for the absence of cash benefit transfers on behalf of the welfare state (Leitner 2005: 365). ${ }^{11}$ Moreover, the net market costs of private services are comparatively high, making it hard even for families with average earnings to afford the purchase of marketable services (Esping-Andersen 1999: 64). On the other hand, tax-based disincentives to female employment are less pronounced than in continental Europe, where an implicit fiscal premium persists for the male breadwinner model. Overall, the heavy weight of the family prescribed by welfare institutions in the fragmented regime is likely to bring about particularly pronounced work-related gender divisions in the Mediterranean countries.

A particularly problematic aspect in most of the welfare regime literature, including the explicitly gender-sensitive contributions, consists in the ontological status of the typology (Crouch 2005). Not always it is clear whether the latter deals with real types or with ideal types. Although Esping-Andersen (1990: 28) admits that there are no "pure cases," welfare regimes are often used in a reifying manner. That is, countries tend to be treated as examples or show cases of ideal types. However, as Crouch (2005) points out, this search for paradigm cases is in conflict with Weber's (1991 [1904]) methodological proposition to create ideal types as stylised and exaggerated descriptions of a phenomenon's key features. In this tradition, hybridisation should be expected to be the norm rather than the exception. Hence, controversies about which regime type fits incoherent cases best (e.g. the Janus-faced Dutch or Swiss welfare states) might be misleading. Finally, another weakness of Esping-Andersen's typology consists in its inability to explain institutional change (Mares 2003; Thelen 2003; Meyer \& Pfau-Effinger 2006).

11 Note, however, that the position of Spain in this respect has changed with the introduction of a public scheme to finance long-term care in 2006. 


\subsection{Summary}

In this chapter, a variety of theoretical approaches, which are pertinent in the field of retirement research, have been presented and discussed. This final section summarises the main insights of the literature review. Table 2.1 gives a schematic overview of the diverse theoretical propositions that have been dealt with above. The theories are sketched here by reference to their central explanans with regard to retirement behavior, the respective key actor(s) involved as well as by the analytical level at which the explanatory mechanism operates. On this basis, I intend to provide a synthetic evaluation of the current state of research on retirement behaviour.

In labour-supply theory, the key mechanism in determining retirement behaviour consists in the responsiveness of individuals to economic incentives. A complex formal apparatus has been elabourated in order to calculate incentive measures, taking into consideration a wide range of parameters including life expectancy, impatience, and risk aversion. Yet at the center of attention is always the design of social-security systems, i.e. institutional features at the macro level. For instance, the comparison of macro-economic externalities and reform scenarios hinges on the simplified model of a stylised rational actor at the micro level. Albeit appropriate for this kind of endeavour, this rigid a priori assumption evidently represents a serious obstacle if the research interest lies precisely in the patterns of social heterogeneity in retirement. Especially, it is unrealistic (and incoherent with existing empirical findings) to assume that individuals can be characterised by identical work-leisure preferences or that every worker has the freedom to voluntarily decide on the time for his or her exit from work. In spite

Table 2.1

Key Features of Theoretical Approaches to Retirement.

\begin{tabular}{|l|c|c|c|}
\hline THeORY & ANALYTICAL LeVel & $\begin{array}{c}\text { CENTRAL } \\
\text { ExPLANANS }\end{array}$ & $\begin{array}{c}\text { KeY } \\
\text { AGENT(S) }\end{array}$ \\
\hline $\begin{array}{l}\text { Labour-supply } \\
\text { Theory }\end{array}$ & Micro/Macro & Financial Incentives & Individual/State \\
\hline $\begin{array}{l}\text { Productivity-based } \\
\text { Approaches }\end{array}$ & Meso & $\begin{array}{c}\text { Productivity } \\
\text { (Health / Skills) }\end{array}$ & Firm \\
\hline $\begin{array}{l}\text { Life Course } \\
\text { Theory }\end{array}$ & Micro/Macro & Norms of Aging & Individual/Society \\
\hline $\begin{array}{l}\text { Welfare-regime } \\
\text { Approach }\end{array}$ & Macro & $\begin{array}{l}\text { Social Policy and Labour } \\
\text { Market Regulation/ } \\
\text { Financial Incentives }\end{array}$ & State \\
\hline
\end{tabular}

Source: own elaboration. 
of these limitations, labour-supply theory is an essential ingredient for research into retirement behaviour, because it explains the degree of attractiveness of different work-exit pathways.

Productivity-based approaches to retirement operate chiefly on the level of the work-place. Specifically, human capital theory posits that investments in the skills of workers determine their productivity and hence their employability. In the main, the retirement age is explained as the consequence of differences in educational assets, which depend on the management of human resources on behalf of the employer as well as on the willingness of employees to engage in further training. However, productivity remains a fuzzy concept that is not very useful for the explanation of social differences in retirement behaviour at the individual level. In fact, despite a good deal of tentative evidence pointing in this direction, there is no hard proof for the widely held assumption that productivity declines with age.

Similarly, the gerontological literature has placed its main emphasis on the implications of working conditions for the health of older workers. The employment chances of senior workers are seen primarily as a function of the firm's production strategies, especially in terms of the effort made to accommodate the particular strengths and weaknesses of an aging workforce. By and large, the labour market opportunities of elderly workers are regarded as the result of company processes. Macro societal configurations, in contrast, are not thoroughly addressed in gerontological or human capital approaches (but cf. Walker 2005). As a consequence, these accounts are not suitable for explaining international diversity in retirement. Moreover, since workers are reduced to their performance capacity, neither approach can account for individual decision-making. In this way, many sources of intra-company variation in workexit dynamics are beyond the scope of human capital or gerontological theory. Still, productivity-based approaches are apt for assessing the variation in workexit dynamics at the firm or industry level. They can be used for the development of hypotheses concerning the influence of the economic sector as well as of education and health on the timing of retirement transitions.

Norms of aging are an essential notion in sociological thinking about retirement. In particular, the life course approach emphasises the normative significance of age boundaries in the context of institutionalised patterns of work biographies. On the one hand, it allows the researcher to account for diverse attitudes towards retirement, which depend on socialisation and labour market experience. On the other hand, the life course approach also addresses the co-evolution of age-graded norms and socio-economic institutions at the societal level. By this token, we gain a deeper understanding of the emergence and historic development of age-related social norms, although the causal direction vis-à-vis institutional regulation is not always unambiguously defined. With respect to the main research question of the present study - the micro 
and macro determinants of retirement timing - a serious shortcoming of the life course approach is the under-conceptualised role of structural constraints. Two important problems arise from this lack of a straightforward way of coping with the structure-agency problem.

Firstly, in spite of the popularity of the age-norms theme in the life course literature, the notion is not consistently embedded in a theoretical model of individual action. Most importantly, it has not been established whether we should think of age-related social norms in a rational-choice fashion as constraints to individual decision-making or rather, as suggested by the frequent juxtaposition with terms like culture, morality, values, etc., as "orienting patterns," i.e. as part of actors' sets of preferences. As a consequence, existing life course research has not been able to systematically assess the scope of age norms in retirement behaviour.

Secondly, the life course approach in itself does not offer an explanatory account of the sources of inequality in economic resources. The diversity of career trajectories is usually recognised, but this notion has rarely been translated into testable hypotheses about social disparities in retirement behaviour. In the next chapter, I shall argue that class theory is ideally suited to fill this gap. The concept of social class is well-equipped to address occupational differences in late-career risks and, hence, in retirement opportunities. Despite being the most prominent measure of social stratification, social class has hardly been employed as analytical category in retirement research thus far. In the following chapter I shall propose to combine the long-standing tradition of class analysis with the life course paradigm into a novel analytical framework for studying differential retirement behaviour. Not least because of the eclecticism of its conceptual toolbox, the life course paradigm is a good starting point for designing an analytical framework for the study of retirement behaviour.

At the macro level, the welfare regime approach offers a stylised categorisation of the various modes of state intervention into the labour market. Esping-Andersen's contribution has inspired fruitful comparative research. Particularly through a dialogue with his feminist critiques, our understanding of the interaction of the welfare state, the market, and the family has been greatly enhanced. The central explanans with regard to retirement is the set-up of social policies and labour market regulation. Whilst implicitly referring to both labour-supply and labour-demand mechanisms, however, the regime approach lacks a consistent account of micro-level processes. National institutional configurations act as a filter for push and pull factors, the tension between which is not dissolved theoretically. The state remains the central actor.

For the study of exit from work transitions, the regime approach is most useful as heuristic device for country comparisons. By providing a well-grounded schema for mapping countries according to institutional characteristics, the regime typology facilitates the generation of hypotheses regarding cross-country 
differences in retirement behaviour. For the sake of analytical rigour, however, the respective patterns of social stratification that allegedly correspond to the different welfare regimes have to be re-interpreted as hypotheses rather than as representing constitutive features of regime types. The discussed criticisms regarding the gender dimension draw attention to an interesting empirical question that shall be addressed in this study, namely, whether the conventional regime typology is appropriate for the analysis of women's exit from work. 